PLAQUE ASSAY, POLYPEPTIDE COMPOSITION AND IMMUNOCHEMISTRY OF FELINE INFECTIOUS PERITONITIS VIRUS AND FELINE ENTERIC CORONAVIRUS ISOLATES

John F. Boyle $e^{1}$, Niels C. Pedersen 1 , James F. Evermann'2, Alison J. McKeirnan ${ }^{2}$, Richard L. Ott2 and John W. Black ${ }^{3}$

${ }^{1}$ Department of Medicine, School of Veterinary Medicine University of California, Davis, CA 95616

2Department of Veterinary Clinical Medicine and Surgery School of Veterinary Medicine, Washington State Univ. Pullman, WA 99164

3Specialized Assays, P.0. Box 25110 Nashville, TN 37202

INTRODUCTION

The coronaviral nature of feline infectious peritonitis virus (FIPV) and feline enteric coronavirus (FECV) has been well documented by morphological, physicochemical and antigenic studies 1 -10. However, biochemical and detailed immunochemical analyses of FIPV and FECV have been difficult due to the inability to prepare sufficient quantities of viral material. Recently, we have been able to propagate FIPV and FECV in continuous cell culture of feline origin $8,11-13$.

The purpose of this report is to describe the purification of feline coronaviruses from infected cell culture and to compare five strains with respect to: 1) plaque characteristics, 2) viral structural polypeptide composition and 3 ) serologic reactivity of experimentally infected cats against the structural polypeptides of homologous and heterologous strains.

MATERIALS AND METHODS

Cells and virus

Fetal cat whole fetus ( $f c w f-4$ ) cells were used to propagate all feline coronavirus strains. Cells were cultured with Eagle's 
mi nimum essential medium supplemented with $20 \%$ Leibovitz's L-15 medium, L-glutamine, antibiotics and $10 \%$ fetal bovine serum (FBS). The isolation and pathogenic characterization of FIPV-UCD1 (UCD1), FIPV Black High passage (BHP), FIPV-Black Low Passage (BLP), FIPV-79-1146 and FECV-79-1683 have been previousiy described $8,9,11-15$.

Titration of virus infectivity

Feline coronaviruses were titered by either dilution to endpoint of infectivity or by plaque assay. For dilution to endpoint titrations, a standard tissue culture infectious dose assay was used. Tissue culture infectious doses for $50 \%$ of the cultures (TCID50) were calculated by the method of Reed and Muench ${ }^{16}$.

Plaque assays were performed in 6 or 12 well Costar cluster plates (Costar, Cambridge, MA). Monolayers of fcwf-4 cel ls were prepared in the plates. The culture medium was aspirated from the wells, and serial five or ten-fold dilutions of virus in Hank's balanced salt solution were inoculated onto the cultures. The inocula were adsorbed for 45 mi nutes at 37 degrees $C$, with occasional rocking. At the end of the adsorption period, the cultures were overlaid with medium containing $0.5 \%$ Noble agar and incubated at 37 degrees $C$ for 1 to 5 days. Overlay medium was then removed, the monolayer rinsed with water, and stained with crystal violet.

Strains UCD1, BLP, BHP, 79-1146 and 79-1683 of feline coronavirus were cultured and plaque picked three times under $0.5 \%$ agar. After the third pick, the virus was inoculated onto monolayers of fcwf-4 cells, allowed to replicate until CPE became apparent and then freeze-thawed at -70 degrees $C$ twice. Clarified culture supernatants were aliquoted and stored at -70 degrees $C$ for later use as stock virus.

Enzyme-1inked immunosorbent assay (ELISA)

An indirect method of ELISA was used for the detection of coronavirus antigen at various stages in the purification. This assay was performed essentially as previously described by Osterhaus et al ${ }^{17}$ and Horzinek et al ${ }^{10}$.

Protein determinations

The Coomassie Blue dye binding method of Bradford ${ }^{18}$ was adapted for use in 96 well round bottom microplates.

Metabolic radiolabeling of virus

Confluent monolayers of fcwf-4 cells were prepared in 
plastic cell culture flasks (Costar, Cambridge, MA). The medium was removed and the cultures were inoculated with a $1: 5$ dilution of the appropriate stock virus. The virus was adsorbed at 37 degrees $C$ for 45 mi nutes with occasional rocking. The inocula were then removed, and Eagle's MEM containing $25 \%$ normal concentration of ami no acids and $2 \%$ dialyzed FBS was added $\left(10 \mathrm{ml} / 75 \mathrm{~cm}^{2}\right)$. The cultures were incubated for 4 hours at 37 degrees $\mathrm{C}$, after which time $2 \mathrm{uCi} / \mathrm{ml}$ of [3H] amino acids was added to the medium. The cultures were harvested soon after CPE was apparent.

\section{Virus purification}

Virus was purified by polyethylene glycol precipitation, a discontinuous sucrose gradient centrifugation step and isopycnic centrifugation in a 20-50 percent (wt/wt) linear sucrose gradient essentially as described by Sturman et al ${ }^{19}$.

SDS - polyacrylamide gel electrophoresis (SDS-PAGE)

Polyacrylamide gradient slab gels $(8-16 \%)$, with $3 \%$ stacking gels, were run using the discontinuous system of Laemmli20. The acrylamide gradient was stablized during pouring with glycerol. Samples were disrupted in treatment buffer for 15 minutes at 25 degrees $C$. The final concentration of the components of the sample treatment buffer were $62.5 \mathrm{mM}$ Tris, 2\% SDS, 2\% 2-mercaptoethanol, 10\% glycerol, $0.01 \%$ bromophenol blue, $\mathrm{pH} 6.8$. The gels were electrophoresed at 15 $\mathrm{mA}$ per gel. Molecular weights were determined using a series of eight molecular weight standards $(200 \mathrm{kd}-14.4 \mathrm{kd}$, Bio Rad, Richmond, CA).

Radioactivity profiles were generated by electrophoresing the proteins of metabolically labeled purified virus in a 1.5 $\mathrm{mm}$ thick $25 \mathrm{~cm}$ long SDS-polyacrylamide gel. The appropriate lane of the slab gel was cut from the gel and sliced horizontally to generate $1.5 \mathrm{~cm} \times .15 \mathrm{~cm} \times .4 \mathrm{~cm}$ pieces. The gel fractions were digested at 37 degrees $C$ for 2 hours with $0.4 \mathrm{ml}$ of NCS tissue solubilizer ( 9 parts NCS: 1 part water, Amersham Corp., Arlington Heights, IL). Ten milliliters of 2 parts PCS: 1 part xylene was used as scintillation fluid. Disintegrations per mi nute were calculated from counts per minute using the external standard channels ratio method.

\section{Immunoblots}

The electrophoretic transfer of proteins from polyacrylamide gels to nitrocel lulose paper and the immunologic detection of the blotted proteins (immunoblotting) was performed similar to the method of Towbin et al 21 . Serum 
samples were diluted 1:50 in dilution buffer consisting of 0.15 M NaCl, 0.05 M Tris, pH 7.4, 0.005 M EDTA, $0.1 \%$ bovine serum albumin and $0.05 \%$ tween 20. 125 labeled rabbit anti-feline IgG was prepared by the chloramine $T$ method 22 and used at a final concentration of $1-5 \times 10^{5} \mathrm{cpm} / \mathrm{ml}$ in dilution buffer.

\section{RESULTS AND DISCUSSION}

Plaque assay of feline coronavi ruses

Plaques produced by 79-1146 and 79-1683 could readily be observed 2 days post infection, while UCD1, BLP and BHP usually took up to 5 days to become large enough to be viewed without the microscope. Plaque size varied considerably between strains but was consistent for each strain. UCD1 and BLP produced small plaques, about $1-2 \mathrm{~mm} 5$ days post-infection. FIPV-BHP which originated from FIPV-BLP stocks, but was passaged in cell culture more than 50 times, has the ability to form slightly larger plaques ( $3 \mathrm{~mm}$ in 5 days). FIPV-79-1146 and FECV-79-1683 produced much larger plaques, >3mm 2 days post infection (Figure 1). Early CPE produced by the five strains consisted of syncytia formation, while later CPE was characterized by rounding of polykaryons and detachment from the plastic substrate (Figure 2). Titers of the stock virus also varied between strains: UCD1 and BLP having low titers $\left(<10^{4} \mathrm{pfu} / \mathrm{ml}\right)$, BHP and 79-1146 having moderate titers (about $\left.10^{5} \mathrm{pfu} / \mathrm{ml}\right)$ and $79-1683$ having the highest titer $\left(>10^{6} \mathrm{pfu} / \mathrm{ml}\right)$.

The results of the plaque assay of the five strains of feline coronavirus we have investigated indicate a great difference in their plaque forming characteristics. Two strains, FIPV-UCD1 and FIPV-BLP, form small plaques and do not replicate to high titer in the culture system used. FIPV-BHP forms a slightly larger plaque and produces moderate titers of virus. The continuous passage of BHP has also caused it to attenyate to the extent that it is no longer pathogenic to cats ${ }^{14}$. Strains $79-1146$ and 79-1683, on the other hand, form large plaques and replicate to high titers. In culture without agar overlay, these strains show extensive CPE 24 hours after infection. This is unlike the other feline coronavirus isolates grown in monolayers without agar overlay. These other isolates do not show CPE until at least 48 hours post infection. The CPE is then limited to small foci of infection which does not appear to spread to other areas of the monolayer, unless the infected cell cultures are passed. This may be due to the low multiplicities of infection (MOI) used, since it is difficult to obtain MOIs greater than 0.002 for these low titer virus strains. Another possible explanation is that FIPV-UCD1 and the Black isolates are highly cell associated, and that transmission to adjacent normal cells 
occurs primarily via fusion with infected cells. On the other hand, FIPV-79-1146 and FECV-79-1683 progeny virions may be more freely released into the medium, thereby infecting cells in more distant areas of the monolayer.
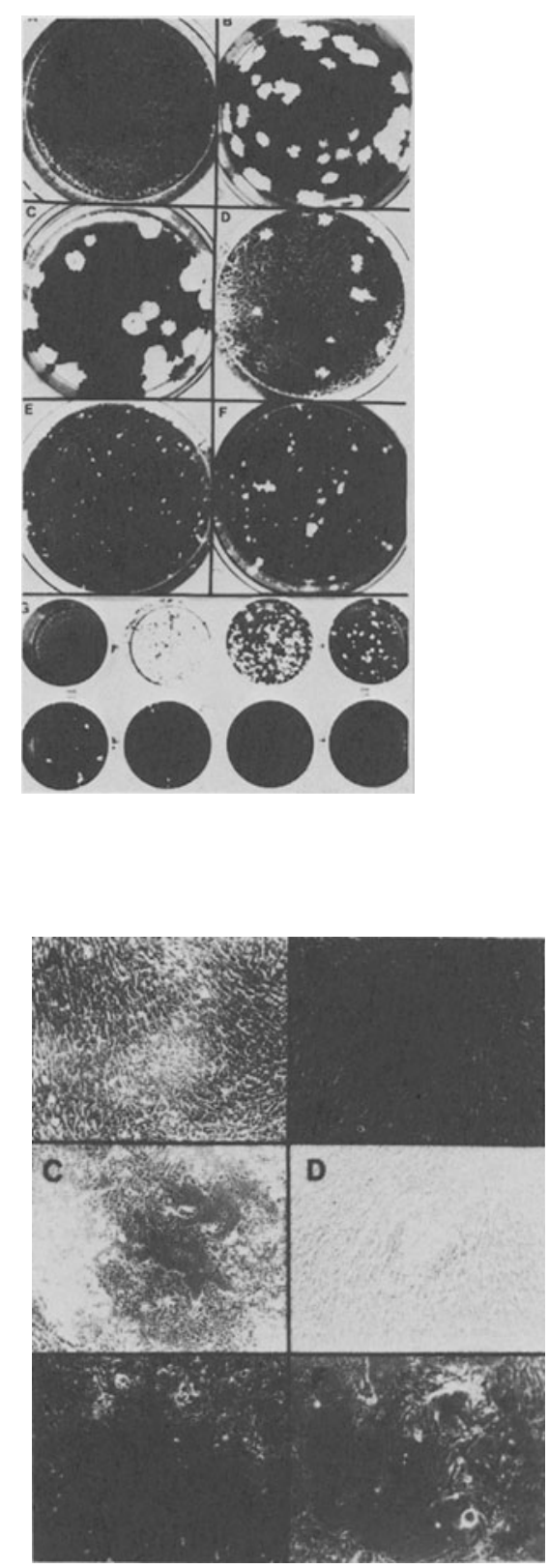

Figure 1. Plaques produced by feline coronaviruses: uninfected monolayer of fcwf cells (A), two days post-infection FIPV-79-1146 (B) and FECV$79-1683$ (C), five days post-infection FIPV-BHP (D), FIPV-BLP (E) and FIPV-UCD1 (F). Plaque assay of FIPV-UCD2, first well was sham inoculated control, subsequent wel 1s inoculated with serial five-fold dilutions $(G)$.

Figure 2. Cytopathic effect of feline coronaviruses: uninfected monolayer of fcwf cells (A), FECV-79-1683; 18 hours post infection (B) and 48 hours post-infection (C), FIPV-UCD1; 48 hours postinfection (D) and 5 days post-inoculation (E), FIPV-BHP; five days postinoculation (F). 
Purification of feline coronavirus from infected cell cultures

The procedure of Sturman et al 19 was used to purify feline coronavirus from infected cell cultures of feline origin. The virus routinely banded at $1.18 \mathrm{~g} / \mathrm{ml}$ in isopycnic sucrose density gradients (Figure 3 ), which has been observed for other members of the Coronaviridae 23,24 .

The recovery of infectious virus from a representative purification is summarized in Table 1. Despite the low percentage of infectious virus recovered from the band in the final centrifugation step (usually about 2\%), the amount of infectious virus per milligram of protein was increased 30 fold. Using methods similar to those applied here, other investigators have reported a much higher percentage recovery of infectious particles after purification than the $2 \%$ observed for FIPV-BHP, i.e., 25\% for TGEV 25 ; $32 \%$ for hemagglutinating encephalomyelitis virus (HEV) of swine 26 , and $66 \%$ for mouse hepatitis virus A59 (MHV-A59) ${ }^{19}$. This may be due the innate lability of the virion. Indeed, negative stain electron microscopy of FIPV-BHP and TGEV purified identically shows that many of the virions in the FIPV preparations are broken open, whereas virions in the TGEV preparations are uniformly intact 27 .

Feline coronavirus polypeptides

The structural proteins that compose the virion of yarious coronaviruses have been analyzed by several laboratories ${ }^{28}$. In general, the coronavirus particle appears to have 4 to 7 proteins. A simple model for the structure of the coronavirion has been proposed by Sturman et al 19 , who suggest that the major viral protein ( $\mathrm{N}$; apparent molecular weight $(\mathrm{Mr})=50 \mathrm{kd}$ ) is associated with the RNA. The nucleocapsid is surrounded by a lipid envelope containing a transmembrane integral glycoprotein (E1; $M r=23 k d$ ) which associates with the nucleocapsid in the interior of the virion while simultaneously exposing a portion of its structure to the external environment. The third and fourth major polypeptides are glycoproteins (E2; Mr=90kd and $180 \mathrm{kd})$. The 180kd molecule is a dimer of the 90kd polypeptide, and together they comprise the characteristic peplomers of the coronavirion 29 .

Radiolabeled polypeptides of UCD1 and BHP were analyzed by SDS-PAGE. Figures 4 and 5 showed that these two strains of feline coronavirus shared the 3 major polypeptides found in many members of the coronaviridae. The major polypeptide, with an apparent molecular weight of 45,000 daltons (45kd) is iikely to be the nucleocapsid protein $(N)$. The small polypeptide, which migrated as a broad band in the range of 33,000 to 27,000 


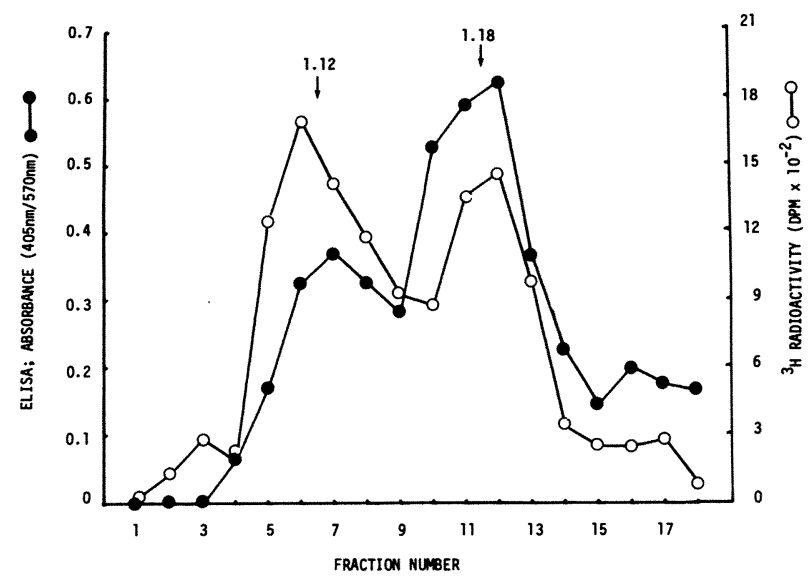

Figure 3. Enzyme-linked immunosorbent assay reactivities and $3_{H}$ radioactivities of fractions from a representative $20-50 \%$ (w/w) linear sucrose gradient used to purify metabolically radiolabeled FIPV-BHP.

daltons is probably the envelope protein (E1), while the large polypeptide, Mr of 210,000 daltons, is most likely the peplomer protein. At the top of the gel, a very large protein was sometimes observed. The molecular weight of this component was difficult to determine precisely, as the highest molecular weight standard used was 200kd, but it is estimated to be at least $400 \mathrm{kd}$. A minor protein, $\mathrm{Mr} 42 \mathrm{kd}$, was also reproducibly seen.

TABLE 1 - FIP virus purification and recovery of infectious virus.

\begin{tabular}{|c|c|c|c|c|c|}
\hline Virus sample & $\begin{array}{c}\text { Infectivity } \\
\left(\mathrm{TCID}_{50} \times 10^{5} / \mathrm{ml}\right)\end{array}$ & $\begin{array}{c}\text { Volume } \\
\text { (ml) }\end{array}$ & $\begin{array}{l}\text { \% Recovery } \\
\text { of infectivity }\end{array}$ & $\begin{array}{l}\text { Total } \\
\text { prote in } \\
(\mathrm{mg})\end{array}$ & $\begin{array}{c}\mathrm{TCID}_{50} \times 10^{5} \\
\mathrm{mg} \text { of } \\
\text { protein }\end{array}$ \\
\hline $\begin{array}{l}\text { Clarified infected } \\
\text { cell culture super- } \\
\text { natant }\end{array}$ & 2.3 & 160 & 100 & 325 & 1.1 \\
\hline $\begin{array}{l}\text { Polyethylene glycol } \\
\text { precipitate }\end{array}$ & 26 & 8 & 57 & 19.6 & 11 \\
\hline $\begin{array}{l}\text { Interphase from 20/50\% } \\
\text { discontinuous sucrose } \\
\text { gradient }\end{array}$ & 18 & 3 & 15 & 1.87 & 29 \\
\hline $\begin{array}{l}\text { Band from 20-50\% } \\
\text { continuous sucrose } \\
\text { gradient } \\
\left(1.175-1.19 \mathrm{~g} / \mathrm{cm}^{3}\right)\end{array}$ & 3.5 & 2 & 2 & 0.23 & 30 \\
\hline
\end{tabular}




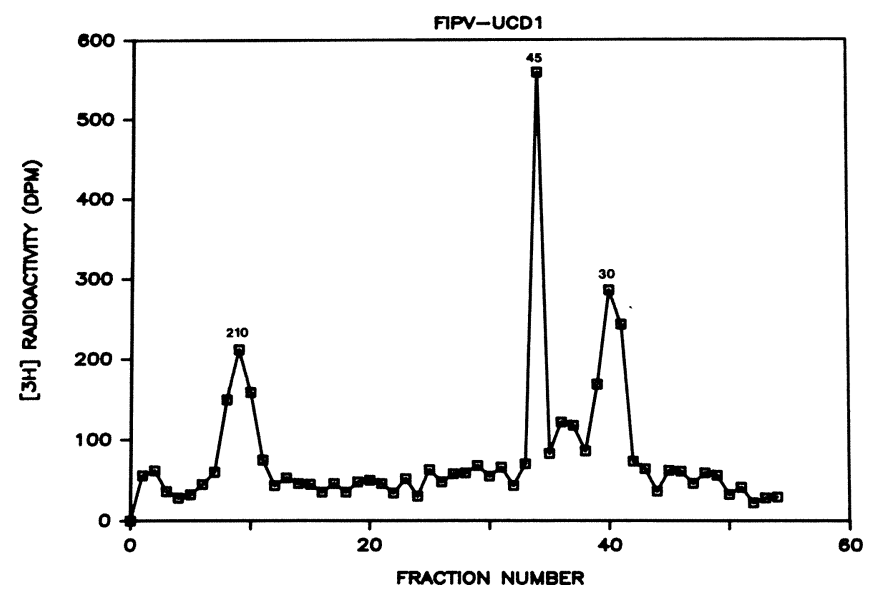

Figure 4. SDS-Polyacrylamide gel electrophoresis profile of ${ }^{3} \mathrm{H}$ amino acid labeled FIPV-UCD1. Numbers above the individual peaks represent molecular weight in kilodaltons.

The polypeptide structure of the feline coronaviruses was confirmed by coupling SDS-PAGE with the ability to detect resolved viral proteins immunologically once they were transferred to nitrocellulose paper (immunoblots). Cell culture material which had been sham inoculated (no virus) and prepared

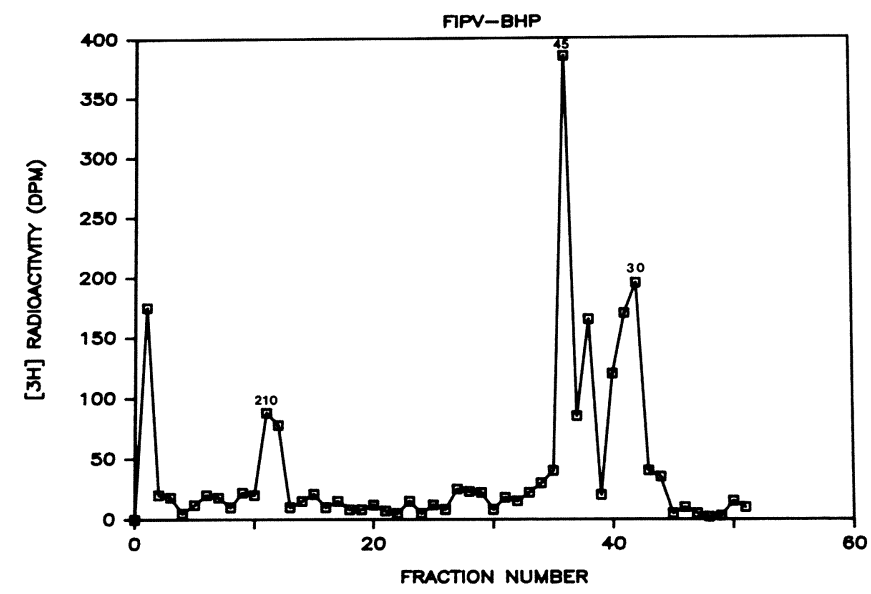

Figure 5. SDS-Polyacrylamide gel electrophoresis profile of ${ }^{3} \mathrm{H}$ amino acid labeled FIPV-BHP. Numbers above the individual peaks represent molecular weight in kilodaltons. 
identically to feline coronavirus preparations was used as a virus negative control. Figure 6 shows the results of an immunoblot in which isopycnically banded FIPV-BHP was detected with various feline anti-coronavirus serum samples. Figures 7 through 9 represent the results of experiments in which five strains of feline coronavirus and sham inoculated cell preparations were electrophoresced in preparative gels, the separated proteins transferred to nitrocellulose and the polypeptides detected with serum samples from various cats. The viral antigen used to generate the blots in figures 7 through 9 was from the $20 / 50 \%$ interface of a discontinuous sucrose gradient. Table 2 summarizes the apparent molecular weights of the proteins for each strain. The nomenclature of Sturman et al ${ }^{11}$ has been used to classify the polypeptides. The most prominent protein (N; Mr 45kd) was recognized by all serum samples used. The broad $30 k d$ band (E1) seen in radioactivity profiles was resolved as a broad triplet. The precise nature of the relationship between the individual components of the E1 complex has not been investigated, but it is likely that differences in the glycosylation in the amino-terminal domain contributes to the polymorphism, as has been demonstrated by Stern et al ${ }^{30}$ for the infectious bronchitis virus (IBV) E1 family.

The large 210kd peplomer protein was detected only when certain serum samples were used. Although the E2 polypeptide was easily seen in [ ${ }^{3} \mathrm{H}$ ] SDS-PAGE profiles of metabolically labeled virus, it was barely detectable in the immunoblots. Three possibilities could contribute to this: (1) inefficient transfer to nitrocellulose paper during blotting, (2) lack of humoral response to this polypeptide by cats infected with feline coronaviruses or (3) loss of critical antigenic determinants during SDS-PAGE or electrophorectic transfer. The first possibility seems least likely, however, since Coomassie Blue staining of gels and amido black staining of nitrocellulose paper after blotting shows that the majority of even the larger molecular weight proteins have left the gel and bound to the nitrocellulose. Also of interest is the fact that no protein was seen which would serve as a likely candidate for a monomer E2 polypeptide as has been demonstrated in the murine coronavirus system ${ }^{29}$.

Other proteins were also readily detected by this technique; $\mathrm{Mr}: 400 \mathrm{kd}, 190 \mathrm{kd}, 162 \mathrm{kd}, 76 \mathrm{kd}, 66 \mathrm{kd}, 57 \mathrm{kd}, 15 \mathrm{kd}, 11 \mathrm{kd}$ and $8 \mathrm{kd}$. However, these are not likely to be viral polypeptides, because: 1) blots using sham inoculated culture material as antigen also contain bands of $190,162,76,66$ and 75kd (Figure 7), 2) infected animals' antibody responses to the 15,11 and 8kd proteins do not increase through the course of infection (Figure 9) and (3) these proteins are not seen in metabolically labeled virus preparations (Figures 4 and 5 ). 

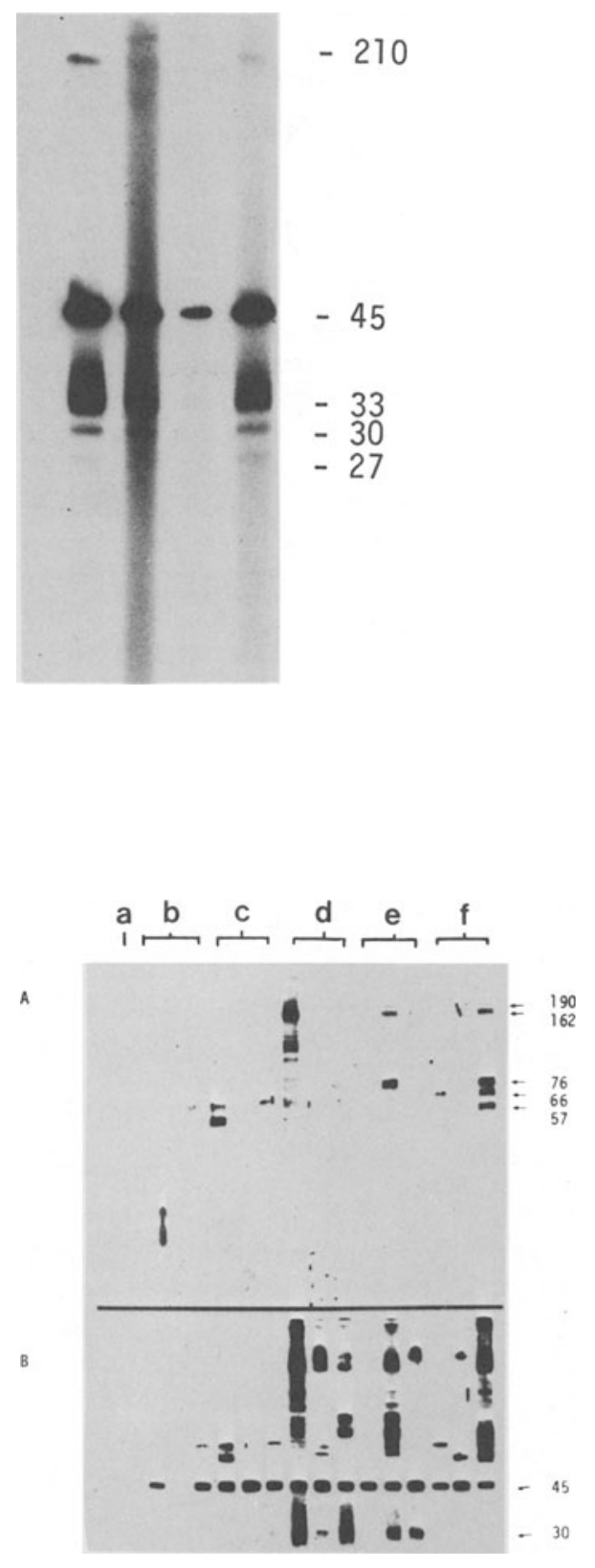

Figure 6. Immunoblot of highly purified FIPV-BHP from the 1.18 $\mathrm{g} / \mathrm{ml}$ fraction of an isopyknic sucrose gradient, reacted with various feline serum samples. Values are apparent molecular weights in kilodaltons.
Figure 7. Immunoblots of sham inoculated fowf cell culture material (panel A) and FIPV-UCD1 inoculated culture material (panel B), reacted with serum samples from cats with the following natural histories: pre-infection (a lane), died FIP; $79-1146$ (b lanes), convalescent FECV; 791683 (c lanes), convalescent FIP; UCD1 (d lanes), died FIP; UCD1 (e lanes) and convalescent FECV; UCD1 (f lanes). Values are apparent molecular weights in kilodaltons. 


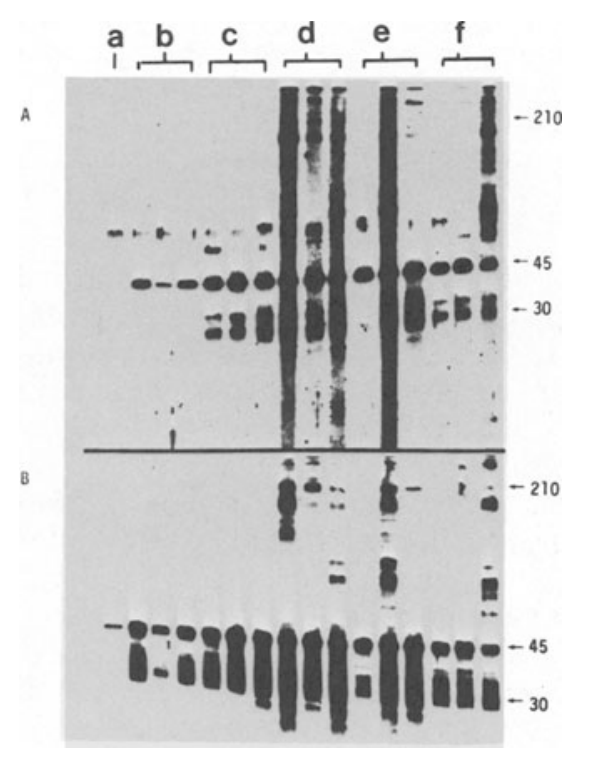

Figure 8. Immunoblots of FIPV-BLP (panel A) and FIPV-BHP (panel B) inoculated cell culture material, reacted with serum samples from cats with the following natural histories: pre-infection (a lane), di ed FIP: $79-1146$ (b lanes), convalescent FECV; $79-1683$ (c lanes), convalescent FIP; UCD1 (d lanes), died FIP; UCD1 (e lanes) and convalescent FECV; UCD1 (f lanes). Values are apparent molecular weights in kilodaltons.

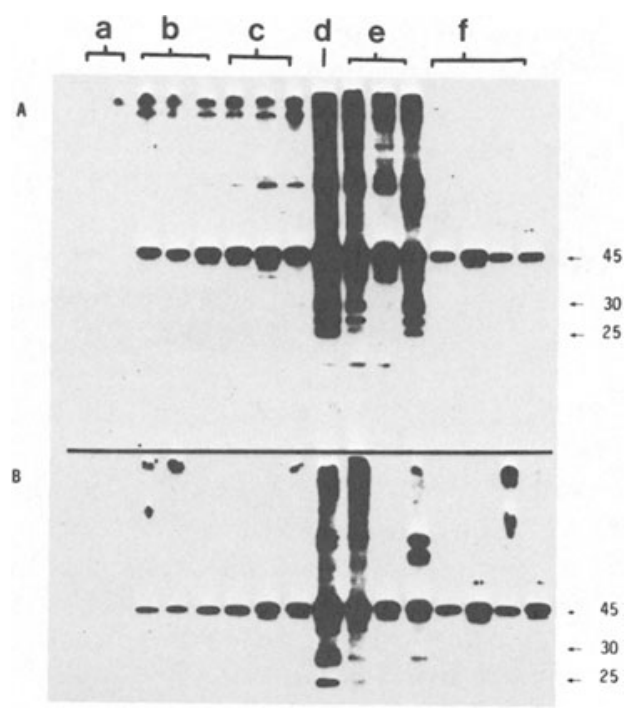

Figure 9. Immunoblots of FIPV-79-1146 (panel A) and FECV-79-1683 (panel B) inoculated cell culture material, reacted with serum samples from cats with the following natural histories: pre-infection (a lanes), died FIP; 79-1146 (b lanes), convalescent FECV; 791683 (c lanes), convalescent FIP; UCD1. (d lane), died FIP; UCD1 (e lanes) and convalescent FECV; UCD1 (f lanes). Values are apparent molecular weights in kilodaltons. 
It therefore appears that the protein structure of the feline coronaviruses is similar to other members of the Coronaviridae 28 .

Comparison of feline serological response to various feline coronavi ruses

Serum samples were collected from cats which had been inoculafed pronasally with various strains of feline coronavirus $9,13,14$. Figures 7 through 9 show the results of immunoblots using convalescent or pre-mortem serum samples from cats infected with the FIPV UCD1, FECV UCD, 79-1146 and 79-1683 to detect homologous and heterologous antigen. Table 3 summarizes the cross-reactivity between heterologous and homologous feline sera and viral antigen preparations. The humoral response of cats to the individual polypeptides of homologous and heterologous virus preparations, as determined by immunoblotting, appeared to be fairly consistent. Animals infected with FIPVUCD1, FECV-UCD, FIPV-79-1146 and FECV-79-1683 all had serum antibodies which recognized the $N$ and $E 1$ proteins of all coronavirus strains used, i.e., FIPV-UCD1, FIPV-BLP, FIPV-BHP, 79-1146 and 79-1683. However, the anti-FIPV-UCD1 and antiFECV-UCD1 samples tended to react more strongly with all of the virus strains. This is most likely due to the fact that these samples had higher titers to coronaviral antigen, as determined by indirect fluorescent and ELISA antibody tests (data not shown).

On the other hand, most animals had very low or undetectable levels of antibodies to the E2 peplomer protein. The only animals that responded to this polypeptide were those infected with FIPV-UCD1 and FECV-UCD1, and these antibodies reacted only with FIPV-UCD1, FIPV-BLP and FIPV-BHP, not with 79-1146 or 791683. This does not necessarily indicate more distant relationship of these strains, because animals infected with 791146 and 79-1683 also did not appear to recognize the homologous E2 antigen. This may be due to the low titers of these serum samples or to loss of critical antigenic determinants during SDS disruption of antigen.

of particular interest is the fact that animals which had died of feline infectious peritonitis and those we considered to be immune to FIP showed comparable humoral reactivity to the individual polypeptides of the virion (Table 3 ). This evidence, along with the observation that high neutralizing antibody titers to FIPV are not protective, supports the hypothesis that cell mediated immunity plays a more important role in the recovery of a cat from infection with FIPV14,15. 
Table 2. Apparent molecular weights of FIPV, FECV and TGEV polypeptides. Values represent $k i l o d a l t o n s, ~ N S=$ not seen.

POLYPEPTIDE

\begin{tabular}{|c|c|c|c|}
\hline STRAIN & N & E1 & E2 \\
\hline FIPV-UCDI & 45 & $\begin{array}{l}32 \\
30\end{array}$ & 210 \\
\hline FIPY-BLP & 45 & $\begin{array}{l}33 \\
30 \\
27\end{array}$ & 210 \\
\hline FIPV-BHP & 45 & $\begin{array}{l}33 \\
30 \\
27\end{array}$ & 210 \\
\hline $79-1146$ & 45 & $\begin{array}{l}30 \\
27 \\
25\end{array}$ & NS \\
\hline $79-1683$ & 45 & $\begin{array}{l}30 \\
27 \\
25\end{array}$ & NS \\
\hline TGEV (Miller) & 48 & $\begin{array}{l}31 \\
27\end{array}$ & 200 \\
\hline
\end{tabular}

Table 3. Summary of cross-reactivity of serum samples from cats infected with various strains of feline coronavirus to heterologous and homologous viral antigen preparations. Convalescent samples were from cats having recovered from experimental infection. Pre-mortem samples were taken from cats in the terminal stages of FIP (experimentally induced) just prior to euthanasia. Cross-reactivity was broken down into 6 categories, by density of the individual bands on the autoradiographs: $++++=$ greatest reactivity, $0=$ no reactivity.

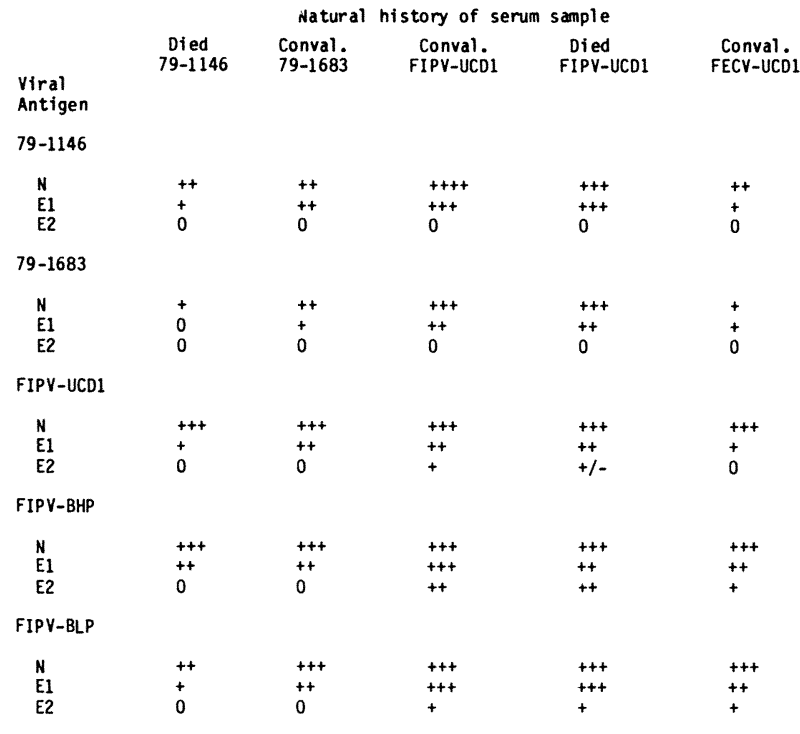




\section{REFERENCES}

1. Ward, J.M. 1970. Morphogenesis of a virus in cats with experimental feline infectious peritonitis. Virol.41:191-194.

2. Zook, B.C., King, N. W., Robison, R.L. and McCombs, H.L. 1968. Ultrastructural evidence for the viral etiology of feline infectious peritonitis. Path. Vet. 5:91-95.

3. Ward, J.M., Munn, R.J., Gribble, D.H. and Dungworth, D.L. 1968. An observation of feline infectious peritonitis. Vet. Record. 83:416-417.

4. Pedersen, N.C. 1976. Morphologic and physical characteristics of feline infectious peritonitis virus and its growth in autochthonous peritoneal cell cultures. Amer. J. Vet. Res. 37:567-572.

5. Horzinek, M.C., Osterhaus, A.D.M.E. and Ellens, D.J. 1977. Feline infectious peritonitis. Zbl. Vet. Med. B. 24:398-405.

6. Reynolds, D.J., Garwes, D.J. and Gaske11, C.J. 1977. Detection of transmissible gastroenteritis neutralizing antibody in cats. Arch. Virol. 55:77.

7. Pedersen, N.C., Ward, J. and Mengeling, W.L. 1978. Antigenic relationship of the feline infectious peritonitis virus to coronaviruses of other species. Arch. Virol. 58:45-53.

8. McKeirnan, A.J., Evemann, J.F., Hargis, A., Miller LM, Ott RL: 1981. Isolation of feline coronaviruses from two cats with diverse disease manifestations. Fel. Prac. 11(3):16-20.

9. Pedersen, N.C., Boyle, J.F. and Floyd, K., Fudge, A. and Barker, J. 1981b. An enteric coronavirus infection of cats and its relationship to feline infectious peritonitis. Amer. J. Vet. Res. $42(3): 368-377$.

10. Horzinek, M.C., Lutz, H. and Pedersen, N.C. 1982. Antigenic relationship among homologous structural polypeptides of porcine, feline and canine coronavirus. Infec. Immun. $37: 1148-1155$.

11. Black, J.W. 1980. Recovery and in vitro cultivation of a coronavirus from lab-induced cases of feline infectious peritonitis. Vet. Med./Sm. Anim. Clin. 75(5):811-814.

12. Evermann, J.F., Baumgartener, L., Ott, R.L., Davis, E.V. and McKeirnan, A.J. 1981. Characterization of a feline infectious peritonitis virus isolate. Vet. Pathol. 18:256-265.

13. Pedersen, N.C., Boyle, J.F. and Floyd, K. 1981a. Infection studies in kittens, using feline infectious peritonitis virus propagated in cell culture. Amer. J. Vet. Res. 42(3):363-367.

14. Pedersen, N.C. and Black, J.W. 1983. Attempted immunization of cats against feline infectious peritonitis using either avirulent live virus of sublethal amounts or virulent virus. Am. J. Vet. Res. 44:229-234.

15. Pedersen, N.L., Black, J.W., Boyle, J.F., Everman, J.F., McKeirnan, A.J. and Ott, R.L.: 1983. Pathogenic differences between various coronavirus isolates. This volume. 
16. Reed, L.J. and Muench, H. 1983. A simple method of estimating fifty percent endpoints. Amer. J. Hygiene. 27:493-497.

17. Osterhaus, A., Kroon, A. and Wirahadiredja, R. 1979. ELISA for the serology of FIP virus. Vet. Quarterly. 1:59-62.

18. Bradford, M.M. 1976. A rapid and sensitive method for the quantitation of protein utilizing the principle of proteindye binding. Anal. Biochem. $72: 248$.

19. Sturman, L.S., Holmes, K.V. and Behnke, J. 1980. Isolation of coronavirus envelope glycoproteins and interaction with the viral nucleocapsid. J. Virol. 33(1):449-462.

20. Laemmli, U.K. 1970. Cleavage of structural proteins during the assembly of the head of bacteriophage T4. Nature. $227: 680-685$.

21. Towbin, H., Staehelin, T. and Gordon, J. 1979. Electrophoretic transfer of proteins from polyacrylamide gels to nitrocellulose sheets: Procedure and some applications. Proc. Nat. Acad. Sci. 76(9):4350-4354.

22. Garvey, J.S., Cremer, N.E. and Sussdorf, D.H., Eds. 1977. 1251 or 1311 labeled proteins. In: Methods in Immunology. W.A. Benjami n, Inc., Massachusetts.

23. Robb, J.A. and Bond, C.W. 1979. Coronaviridae. In Comprehensive Virology. Vol. 14, pp 193-247. Edited by $H$. Fraenkel-Conrat and R. R. Wagner. New York: Plenum Press.

24. Tyrrell, D.A.J., Tyrrell D.A.J., Alexander D.J., Almeida J.D., Cunningham C.H., Easterday B.C., Garwes D.J., Hierholzer J.C., Kapikian A., MacNaughton M.R. and McIntosh K.: 1978. Coronaviridae: Second report. Intervirology. 10:321-328.

25. Garwes, D.J. and Pocock, D.H. 1975. The polypeptide structure of transmissible gastroenteritis virus. J. Gen. Virol. 29:25-34.

26. Pocock, D.H. and Garwes, D.J. 1977. The polypeptides of hemagglutinating encephalomyelitis virus and isolated subviral particles. J. Gen. Virol. 37:487-499.

27. Boyle, J.F. 1982. Ph.D. dissertation: Aspects of the pathogenesis and biology of feline infectious peritonitis virus and feline enteric coronavirus. University of California, Davis.

28. Mahy, B.W.J. 1981. Biochemistry of coronaviruses 1980. In: Biochemistry and Biology of Coronaviruses. V. ter Meulen, S. Siddell and H. Wedge, Eds. Plenum Press. New York.

29. Sturman, L.S. and Holmes, K.V. 1977. Characterization of a coronavirus. II. Glycoproteins of the viral envelope: Tryptic peptide analysis. Virol. 77:650-660.

30. Stern, D.F., Burgess, L. and Stefton, B. 1982. Structural analysis of virion proteins of the avian coronavirus infectious bronchitis virus. J. Virol . 42(1): $208-219$. 